\title{
(6) OPEN ACCESS \\ Tobacco retail policy landscape: a longitudinal survey of US states
}

\author{
Douglas A Luke, ${ }^{1}$ Amy A Sorg, ${ }^{1}$ Todd Combs, ${ }^{1}$ Christopher B Robichaux, ${ }^{1}$ \\ Sarah Moreland-Russell, ${ }^{1}$ Kurt M Ribisl, ${ }^{2,3}$ Lisa Henriksen $^{4}$
}

${ }^{1}$ Center for Public Health Systems Science, George Warren Brown School of Social Work, Washington University in St Louis, St Louis, Missouri, USA

${ }^{2}$ Gillings School of Global Public Health, University of North Carolina, Chapel Hill, North Carolina, USA

${ }^{3}$ Lineberger Comprehensive Cancer Center, University of North Carolina, Chapel Hill, North Carolina, USA ${ }^{4}$ Stanford Prevention Research Center, Stanford University School of Medicine, Palo Alto, California, USA

\section{Correspondence to} Dr Douglas A Luke, Center for Public Health Systems Science, Washington University in St Louis, Campus Box 1196, One Brookings Drive, St Louis, MO 63130,USA; dluke@wustl.edu

Received 28 March 2016 Accepted 28 June 2016

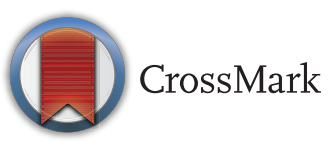

To cite: Luke DA, Sorg AA, Combs T, et al. Tob Control 2016:25:i44-i51.

\section{ABSTRACT}

Background There are $\sim 380000$ tobacco retailers in the USA, where the largest tobacco companies spend almost $\$ 9$ billion a year to promote their products. No systematic survey has been conducted of state-level activities to regulate the retail environment, thus little is known about what policies are being planned, proposed or implemented.

Methods This longitudinal study is the first US survey of state tobacco control programmes (TCPs) about retail policy activities. Surveyed in 2012 and 2014, programme managers $(n=46)$ reported activities in multiple domains: e-cigarettes, retailer density and licensing, non-tax price increases, product placement, advertising and promotion, health warnings and other approaches. Policy activities were reported in one of five levels: no formal activity, planning or advocating, policy was proposed, policy was enacted or policy was implemented. Overall and domainspecific activity scores were calculated for each state.

Results The average retail policy activity almost doubled between 2012 and 2014. States with the largest increase in scores included: Minnesota, which established a fee-based tobacco retail licensing system and banned self-service for e-cigarettes and all other tobacco products (OTP); Oregon, Kansas and Maine, all of which banned self-service for OTP; and West Virginia, which banned some types of flavoured OTP.

Conclusions Retail policy activities in US states increased dramatically in a short time. Given what is known about the impact of the retail environment on tobacco use by youth and adults, state and local TCPs may want diversify policy priorities by implementing retail policies alongside tax and smoke-free air laws.

\section{INTRODUCTION}

The retail environment is the primary channel for tobacco marketing, advertising and promotional efforts, and subject to few regulations. ${ }^{1-3}$ After the 1998 Master Settlement Agreement placed limits on many areas of tobacco advertising in the USA (eg, banning ads on billboards and transit), the tobacco industry directed an increasing amount of advertising and promotional expenditure towards the relatively unregulated retail environment. ${ }^{4}{ }^{5}$ In 2013, the industry spent over $\$ 8.62$ billion at retail, including cigarette and smokeless marketing, advertising and promotion. ${ }^{126}$ Retail tobacco marketing and tobacco retailer proximity or density increase youth and adult tobacco use, prompt impulse pur-

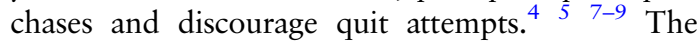
industry's influence over the retail environment also contributes to tobacco-related disparities with higher tobacco retailer density and targeted marketing found in minority and low-income neighbourhoods. 25 10-12

Given what is known about the impact of the retail environment on tobacco use by youth and adults, there is an increased need for regulation focused on the retail environment. ${ }^{13}{ }^{14}$ Until recently, US retail tobacco policies have concentrated on limiting youth access to tobacco products. ${ }^{15} 16$ However, the 2009 Family Smoking Prevention and Tobacco Control Act (FSPTCA) has clarified the authority that states and communities have to adopt new policies that restrict the time, place and manner of tobacco advertising and promotions. ${ }^{17} 18$ Other types of policies to regulate the retail environment for tobacco can decrease tobacco retailer density, increase tobacco product prices through non-tax approaches ${ }^{19}$ and extend laws that specifically pertain to cigarettes to all tobacco and other products, including cigars, snuff and e-cigarettes. A number of these policy priorities are not addressed by federal laws and thus are consigned to states and communities for regulation.

In the USA, previous research assessed state readiness to adopt tobacco control policies ${ }^{20}$ and state priorities for research to inform e-cigarette regulation, ${ }^{21}$ although a comprehensive examination of state-level retail policy activity has not occurred prior to this study. While many localities are developing and implementing policies, they often look to their own and other states' agencies for precedents and guidance. ${ }^{22} 23$ This study is the first to provide a detailed assessment of state-level activities in this new policy area and to compare retail policy activities as a function of progress in other tobacco control policy domains (eg, tax and smoke-free air).

Successful retail policies can directly address the environmental and social factors that contribute to tobacco use while complementing traditional tobacco control approaches. For example, of the 28 states that attempted to pass a tobacco tax increase in 2015, only 8 succeeded. $^{24}$ Thus, enacting a minimum price and/or minimum pack size is an alternative to increase the price of cheap tobacco products when tax increases fail. Consideration of retail policies by all states is important given the massive amount of tobacco industry spending in this area, and momentum from states that have already achieved successful smoke-free and excise tax policies can be harnessed to further reduce industry influence. We identify different types of retail policy environments and present them in the context of other existing policy efforts such as tax and smoke-free air, to enable state programmes to judge their readiness for new retail policy efforts. 
This research is timely given that the Centers for Disease Control included retail initiatives in its cooperative agreement that guides all state tobacco control efforts. ${ }^{25}$ This research could also shape the discussion around retail policies for policymakers and inform future funding efforts. Furthermore, state and local tobacco control advocates can gain a better awareness of retail policy activity occurring throughout the USA and assess their progress relative to others.

\section{Study context}

This study uses data from Advancing Science and Policy in the Retail Environment (ASPiRE), which is funded by the National Cancer Institute's State and Community Tobacco Control (SCTC) Research Initiative. ASPiRE is a consortium of researchers from the Center for Public Health Systems Science (CPHSS) at Washington University in St Louis, the Stanford Prevention Research Center and the University of North Carolina Gillings School of Global Public Health who conduct research on how to maximise state and local policies to restrict tobacco marketing in the retail environment. CPHSS led this study, which provides the first nationwide review of state-level retail policy activity and demonstrates an increase in these activities over a 2-year timespan.

\section{METHODS}

\section{Instrument development}

The wave I survey assessed activity for 25 possible policy options that were then grouped into six broad policy domains. Specific policy options and policy domains were informed by retail policy experts and members of an advisory board comprised of state and local tobacco control programmes (TCPs), researchers, legal experts and advocates. To be responsive to wave I responses and better assess changes in the policy and retail environments over time, the wave II instrument contained 33 policy options across seven domains, including e-cigarettes. Table 1 lists domain descriptions and constituent policy options.

Policy activities were scored on a five-point continuum:

1. No formal activities: refers to general information gathering and fact finding, but no formal activities on the specific policy option have been completed.

2. Planning/advocating: refers to planning and advocating activities (eg, partnership development, informal education of policymakers) focused on the specific policy option.

3. Policy proposed: refers to a specific policy that has been developed and proposed to a legislative body/decisionmakers; this includes policies that are currently being considered and that have been proposed but failed to be enacted.

4. Policy enacted: refers to a law, resolution or ordinance that has passed or received formal approval.

5. Policy implemented: refers to a law, resolution or ordinance that has passed and been implemented or otherwise put into action.

\section{Survey participants and data collection}

CPHSS staff conducted interviews with a state TCP director, manager or coordinator from April 2012 through September 2012 and again from August 2014 through October 2014. To aid the recruitment and interview process, CPHSS staff sent a copy of the survey via email to each participant a few weeks prior to the scheduled interview. Interviews were recorded and transcribed. For wave I, respondents from TCPs in 48 (96\%) states (all except Connecticut and Virginia) agreed to complete the survey (44 by phone and 4 via email). For wave II, 48 respondents agreed to complete the survey (except Ohio and Pennsylvania). In all, 46 (92\%) states participated in both surveys by phone or email.

\section{Data management and analysis}

For each specific retail policy activity, a policy score was assigned based on the highest activity level reported for the past 12 months (no formal activity=0, planning/advocating=1, policy proposed $=2$, policy enacted $=3$, policy implemented $=4$ ). For example, states that had implemented tobacco retail licensing fees were assigned 4 , and those planning to establish fees for the first time were assigned 1 . Casting a wide net, we did not qualitatively assess the strength of implemented policies. A 4 is the highest score a state can receive for any one policy, so once it is assigned a '4' for having a policy implemented, this value does not change unless that policy is repealed. To clarify, a state with previously established licensing fees that was also planning to increase those fees would still receive a '4' for that policy. Each policy option score was then combined to create an overall Retail Policy Activity Score. In light of the additional policy domains included in 2014, scores were normalised by the total possible points for each wave to facilitate comparisons. Like a percentage, the range of the Retail Policy Activity Scores is 0 to 100. A score of 0 indicates that a state reported no policies implemented and no formal planning going on for retail policy work. A score of 100 would indicate that a state had implemented all of the retail policy options in the survey.

\section{RESULTS}

While $89 \%$ of states reported some retail policy activity in 2012, 100\% of states reported some activity by 2014 (figure 1). Overall, states were most active in their efforts to regulate ecigarettes and to reduce or restrict the number, location, density and type of tobacco retail outlets. Policy efforts around graphic health warnings and restricting retail advertising were the least active areas of effort. The domains with the largest increases in reported activity over the 2 years were product placement and the 'other' (miscellaneous) policy categories. Table 1 presents the proportion of states reporting policy planning or proposal activities and passed policies (enacted or implemented) for each of the 33 specific retail policy options.

\section{e-Cigarettes}

All but two states reported policy activity focused on e-cigarettes in 2014, making this new policy domain (added in wave II) the most active of 2014. By then, minimum legal sales or access age (MLA) laws for e-cigarettes were reported by three-quarters (76\%) of the states. In most cases, the MLA for e-cigarettes matches existing tobacco control laws and bans sales to individuals under 18 years old. Many states are also addressing selfservice for e-cigarette products; of the 19 states that have been planning policies banning self-service, 12 (26\% of states) have succeeded. Two states (Minnesota and North Carolina) have established an excise tax on e-cigarettes, and five require licensing for e-cigarette sales.

\section{Tobacco retailer density and licensing}

Most states (80\%) reported policy activity in the licensing and retailer density policy domain for 2014. Over half of states (63\%) described having licensing fees for tobacco retailers. Three states (Hawaii, Indiana and Utah) reported having narrowly crafted laws that establish minimum distance between certain types of retailers and places youth frequent, like parks and schools. Many other states reported planning activities 
Table 1 Retail policy domains and options $(\mathrm{N}=46)^{*}$

\begin{tabular}{|c|c|c|c|c|}
\hline & \multicolumn{4}{|c|}{ States reporting activity } \\
\hline & \multicolumn{2}{|l|}{2012} & \multicolumn{2}{|l|}{2014} \\
\hline & Plan/proposed (\%) & Passed (\%) & Plan/proposed (\%) & Passed (\%) \\
\hline \multicolumn{5}{|l|}{$\begin{array}{l}\text { E-cigarettes } \\
\text { Policies that may be used to regulate electronic smoking devices }\end{array}$} \\
\hline - Regulate minimum age to buy e-cigarettes and related products & - & - & 17 & 76 \\
\hline - Ban self-service displays for e-cigarettes & - & - & 15 & 26 \\
\hline - Require licensing for e-cigarette sales & - & - & 30 & 11 \\
\hline - Establish a tax on e-cigarettes & - & - & 39 & 7 \\
\hline - Regulate where e-cigarettes are sold (eg, retailer type, youth locales) & - & - & 9 & 0 \\
\hline \multicolumn{5}{|c|}{$\begin{array}{l}\text { Tobacco retailer density and licensing } \\
\text { Policies that affect the presence of retailers by reducing (or restricting) the number, location, density or types of tobacco retail outlets }\end{array}$} \\
\hline - Establish or increasing licensing fees & 9 & 57 & 13 & 63 \\
\hline - Prohibit tobacco sales in locations youth frequent & 15 & 17 & 28 & 7 \\
\hline - Require certain distance between tobacco retailers & 17 & 0 & 7 & 2 \\
\hline - Restrict retailers in certain zones (eg, banning in residential zones) & 11 & 0 & 7 & 2 \\
\hline - Prohibit tobacco sales at certain establishment types (eg, pharmacies) & 9 & 0 & 15 & 0 \\
\hline - Limit or capping the total number of licenses in a specific area & 13 & 0 & 17 & 0 \\
\hline Limit number of hours or days in which tobacco can be sold & 0 & 0 & 2 & 0 \\
\hline \multicolumn{5}{|c|}{$\begin{array}{l}\text { Non-tax price increases } \\
\text { Policies that use non-tax strategies to reduce consumption by raising the price of tobacco products }\end{array}$} \\
\hline - Establish cigarette minimum price laws & 7 & 46 & 9 & 46 \\
\hline - Ban price discounting/multipack options & 9 & 0 & 20 & 0 \\
\hline - Ban distribution of coupons $\dagger$ & - & - & 7 & 7 \\
\hline - Ban redemption of couponst & - & - & 13 & 0 \\
\hline - Ban use of couponst & 2 & 9 & - & - \\
\hline - Require disclosure for manufacturer to retailer incentives & 0 & 0 & 7 & 0 \\
\hline - Establish mitigation fees (eg, a fee to clean up cigarette litter) & 2 & 0 & 0 & 0 \\
\hline \multicolumn{5}{|c|}{$\begin{array}{l}\text { Product placement } \\
\text { Policies that limit how, where, and when tobacco products are displayed in the retail environment }\end{array}$} \\
\hline - Ban self-service displays for OTPs & 13 & 20 & 13 & 46 \\
\hline - Ban product displays (eg, tobacco behind opaque shelving) & 13 & 0 & 7 & 0 \\
\hline - Restrict the number of products that can be displayed & 4 & 0 & 2 & 0 \\
\hline - Limit times during which products are visible (eg, after school hours) & 0 & 0 & 0 & 0 \\
\hline \multicolumn{5}{|c|}{$\begin{array}{l}\text { Advertising and promotion } \\
\text { Policies that limit the permitted times, placement, and/or manner of tobacco retail advertising }\end{array}$} \\
\hline - Content-neutral ad restrictions (eg, restrict to $15 \%$ of window area) & 2 & 2 & 2 & 2 \\
\hline - Limit placement of ads at certain locations (eg, $1000 \mathrm{ft}$ of schools) & 4 & 0 & 13 & 0 \\
\hline - Limit placement of outdoor store ads & 4 & 0 & 9 & 0 \\
\hline - Limit the placement of ads within the store (eg, near cash register) & 4 & 0 & 9 & 0 \\
\hline - Limit manner of ads (certain types eg, sandwich board style ads) & 0 & 0 & 7 & 0 \\
\hline - Limit the times advertising is permitted (eg, after school hours) & 0 & 0 & 0 & 0 \\
\hline \multicolumn{5}{|c|}{$\begin{array}{l}\text { Health warnings } \\
\text { Policies that use health warnings, cessation services information, or other resources to alert customers in the retail environment. }\end{array}$} \\
\hline - Require graphic warnings at the point of sale & 9 & 0 & 4 & 0 \\
\hline - Require the posting of quit line information in tobacco retail stores & - & - & 9 & 2 \\
\hline \multicolumn{5}{|l|}{$\begin{array}{l}\text { Other approaches } \\
\text { Miscellaneous policies for the retail environment }\end{array}$} \\
\hline - Raise the minimum legal sale age (MLA) to buy tobacco products & - & - & 28 & 9 \\
\hline - Require minimum pack size for OTPs & 2 & 2 & 13 & 7 \\
\hline - Ban flavoured OTPs & 22 & 2 & 26 & 4 \\
\hline
\end{tabular}

'-' indicates that question was not asked in the specific wave.

${ }^{*} \mathrm{CT}$ and VA did not interview in 2012; OH and PA did not interview in 2014.

†After learning that some states had or were working on coupon 'distribution' bans in 2012, and others were working on coupon 'redemption' bans, we split 'banning use of coupons' into these separate options in 2014.

focused on adopting similar retail distance policies. Eight states reported activities towards policies that prohibit tobacco sales at certain establishment types, such as pharmacies, and six states reported policy activity that limit or cap the total number of tobacco retailer licenses.
Raising tobacco prices through non-tax approaches

More than half of states (59\%) reported policy activity or implementation of non-tax approaches for increasing retail prices. However, most of this activity referred to minimum price laws that were passed many years ago and have not been very effective 


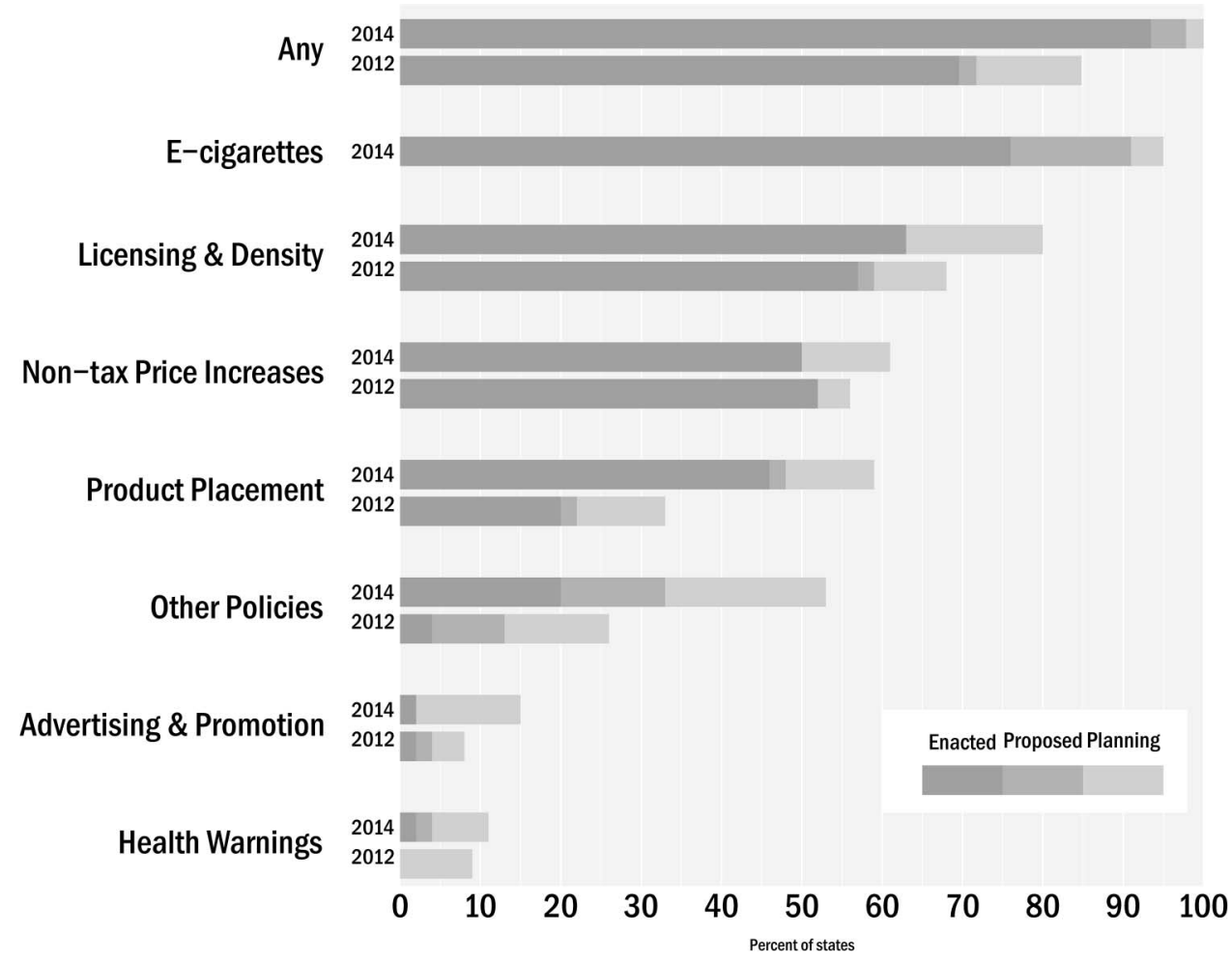

Figure 1 Percentage of states reporting retail policy activity by policy domain $(n=46)$.

in raising prices. ${ }^{26} 27$ Other activities included policy planning around limiting price discounts, including restricting the distribution and/or redemption of coupons. Overall, there was little reported change in non-tax approaches between 2012 and 2014.

\section{Restricting product placement}

Most activity in the product placement policy domain involved restricting self-service for other tobacco products (OTPs). Twenty-one states (46\%) now ban self-service displays and six more reported planning for similar policies in 2014. Because of this issue, in particular, the product placement domain saw the largest reported increase in state-level policy activity between 2012 and 2014.

\section{Restricting retail advertising}

Only 9\% of states in 2012 and 15\% of states in 2014 reported any policy activity directed at advertising and promotion. Much of the current and newly reported work in this domain attempts to reduce advertising near places that youth frequent like parks and schools.

\section{Implementing retail health warnings}

The policy domain with the least activity includes posting of health information at tobacco retailers. Four states (9\%) reported planning around requiring health warnings on signs in tobacco retailers in 2012 and only two states reported activity in 2014. In addition, five states reported activity that required the posting of quitline information in tobacco retailers in 2014 , and one state (Indiana) had succeeded in implementing that policy.

\section{Other retail policies}

Policies to ban flavours and to establish minimum packaging requirements for OTPs also saw activity between the two survey waves. By 2014, 30\% and 20\% of states reported ongoing efforts to ban flavoured OTPs and regulate pack sizes for OTPs, respectively. Two states (Maine and West Virginia) have implemented policies that ban all or some types of flavoured OTPs. Some of the increase in this 'catch-all' policy domain was due to the addition of a survey item in wave II that assessed efforts to raise the MLA for tobacco in which $37 \%$ of states reported activity. Only about a quarter of states (26\%) reported any activity in this domain in 2012.

Retail policy activity by state

The overall Retail Policy Activity Score was used to explore policy activities across states, as well as to examine change in activity over time. Between 2012 and 2014, the average policy scores increased from 7.8 to 13.1 , an increase of $168 \%$ (figure 2). In 2012, seven states received a zero score for no reported policy activity. However, all states in 2014 received a positive policy score, indicating that some sort of policy activity was occurring in every state across the country. Three states had scores of 20 or above (on a scale of 1-100) in 2012: Maryland (21), New York (23) and California (25). In 2014, eight states scored 20 or higher, and Vermont had the highest score of 31. States with the largest increase in scores over the 2 years include: Minnesota, which established a fee-based tobacco retail licensing system and banned self-service for e-cigarettes and all OTPs; Oregon, Kansas and Maine, which banned self-service for OTPs; and West Virginia, which banned some types of flavoured OTPs.

Examining retail policy activity in the context of tax and smoke-free air

Figure 3 illustrates the relationship between each state's Retail Policy Activity Score, ${ }^{28}$ cigarette excise $\operatorname{tax}^{28}$ and strength of smoke-free air laws as measured by the American Lung Association (American Lung Association, Unpublished data, provided on request, 2015). The figure is divided into four 

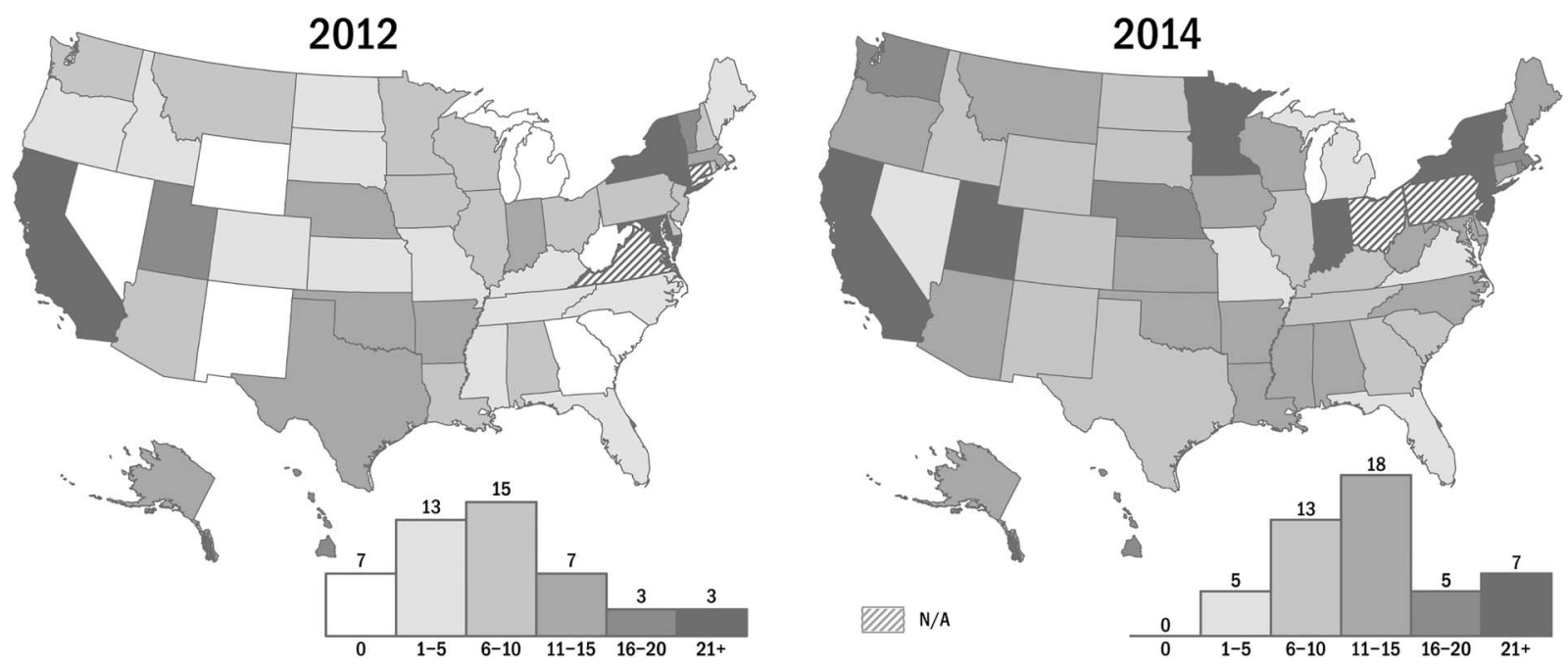

Figure 2 Variability of retail policy activity and 2-year changes across the USA.

quadrants by the median tax $(\$ 1.35)$ and the median 'Smokefree Air' score (91). This score was standardised so that all states had the same maximum possible score. Each state's Retail Policy Activity Score is represented by a graduated circle, with larger circles reflecting greater retail policy activity.

The figure suggests a framework for how to consider staging states for future policy activity. States in or near quadrant I have already achieved some measure of policy success by implementing smoke-free air policies and relatively high excise taxes. Many of the top scorers are also found in quadrant I, and states in this quadrant (noted in white) appear to be wellpositioned to consider expanding their efforts into the retail policy area.

However, states in the other quadrants may also benefit from incorporating retail policy activities into their current tobacco control programming. As per CDC's Best Practices evidence-
Figure 3 Identification of 'retail-ready' states.

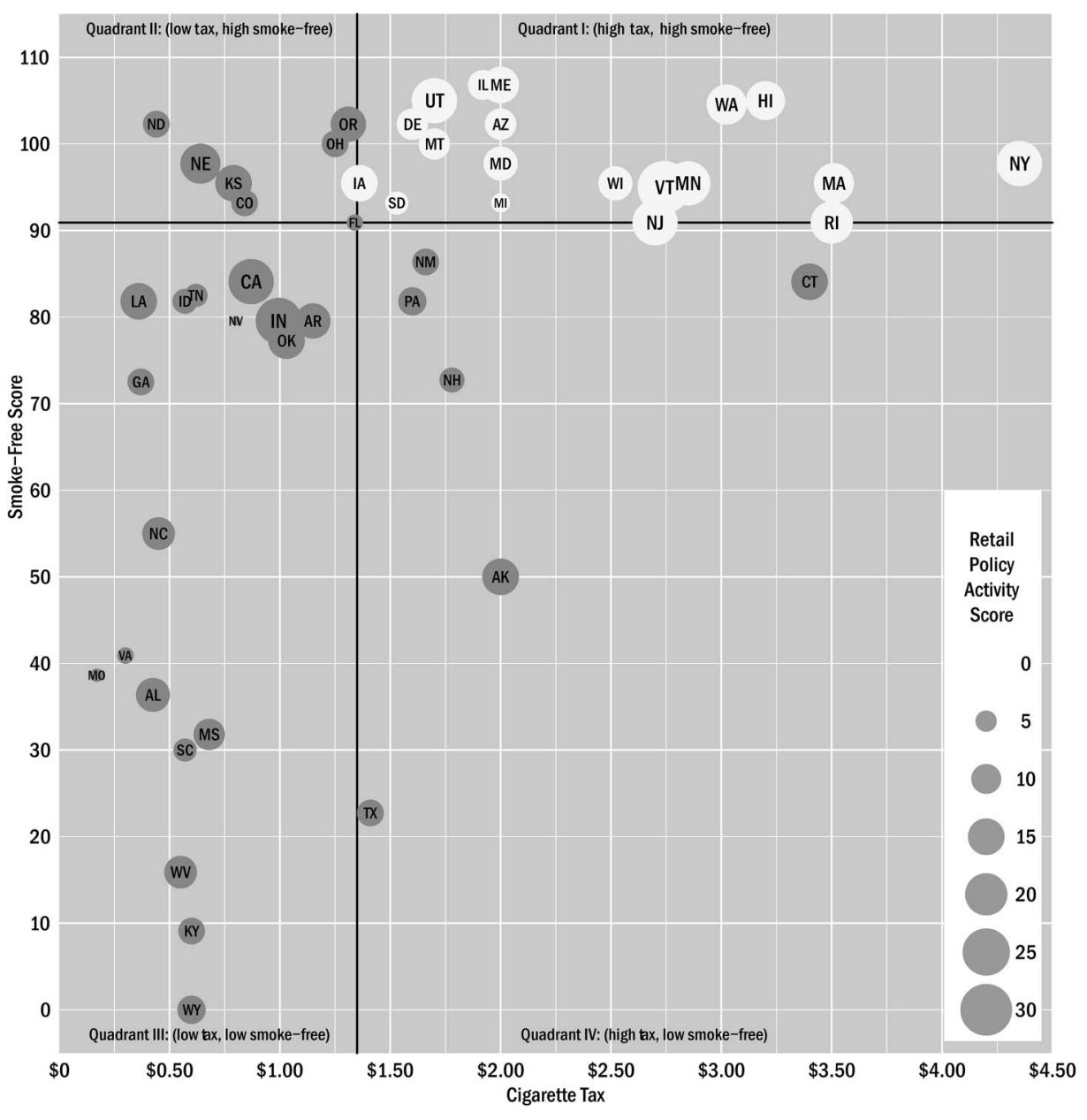

Luke DA, et al. Tob Control 2016;25:i44-i51. doi:10.1136/tobaccocontrol-2016-053075 
based guidelines, ${ }^{29}$ these states should continue to address these policy areas, but may consider adding retail policy work as funding and time allow. Table 2 lists all state scores by quadrant.

Table 2 State policy scores, smoke-free scores and tax in 2014

\begin{tabular}{|c|c|c|c|}
\hline State & $\begin{array}{l}\text { Retail policy } \\
\text { activity score }\end{array}$ & $\begin{array}{l}\text { Smoke-free } \\
\text { score }\end{array}$ & $\begin{array}{l}\text { Cig. excise } \\
\operatorname{tax}(\$)\end{array}$ \\
\hline \multicolumn{4}{|c|}{ Quadrant I (high tax, high smoke-free) } \\
\hline Michigan & 4 & 93 & 2.00 \\
\hline South Dakota & 6 & 93 & 1.53 \\
\hline Illinois & 10 & 107 & 1.98 \\
\hline Arizona & 11 & 102 & 2.00 \\
\hline Delaware & 11 & 102 & 1.60 \\
\hline Montana & 11 & 100 & 1.70 \\
\hline Maryland & 13 & 98 & 2.00 \\
\hline Wisconsin & 13 & 95 & 2.52 \\
\hline lowa & 15 & 95 & 1.36 \\
\hline Maine & 15 & 107 & 2.00 \\
\hline Hawaii & 17 & 105 & 3.20 \\
\hline Massachusetts & 18 & 95 & 3.51 \\
\hline Washington & 18 & 105 & 3.03 \\
\hline Rhode Island & 20 & 91 & 3.50 \\
\hline Minnesota & 22 & 95 & 2.83 \\
\hline New Jersey & 23 & 91 & 2.70 \\
\hline New York & 23 & 98 & 4.35 \\
\hline Utah & 23 & 105 & 1.70 \\
\hline Vermont & 31 & 95 & 2.75 \\
\hline \multicolumn{4}{|c|}{ Quadrant II (low tax, high smoke-free) } \\
\hline Florida & 3 & 91 & 1.34 \\
\hline Colorado & 8 & 93 & 0.84 \\
\hline North Dakota & 8 & 102 & 0.44 \\
\hline Ohio* & 8 & 100 & 1.25 \\
\hline Oregon & 14 & 102 & 1.31 \\
\hline Kansas & 15 & 95 & 0.79 \\
\hline Nebraska & 18 & 98 & 0.64 \\
\hline \multicolumn{4}{|c|}{ Quadrant III (low tax, low smoke-free) } \\
\hline Nevada & 1 & 80 & 0.80 \\
\hline Missouri & 2 & 39 & 0.17 \\
\hline Virginia & 3 & 41 & 0.30 \\
\hline South Carolina & 6 & 30 & 0.57 \\
\hline Tennessee & 6 & 83 & 0.62 \\
\hline Idaho & 7 & 82 & 0.57 \\
\hline Georgia & 8 & 73 & 0.37 \\
\hline Kentucky & 8 & 9 & 0.60 \\
\hline Wyoming & 9 & 0 & 0.60 \\
\hline Mississippi & 11 & 32 & 0.68 \\
\hline North Carolina & 12 & 55 & 0.45 \\
\hline West Virginia & 12 & 16 & 0.55 \\
\hline Alabama & 13 & 36 & 0.43 \\
\hline Arkansas & 14 & 80 & 1.15 \\
\hline Louisiana & 15 & 82 & 0.36 \\
\hline Oklahoma & 15 & 77 & 1.03 \\
\hline California & 23 & 84 & 0.87 \\
\hline Indiana & 23 & 80 & 1.00 \\
\hline \multicolumn{4}{|c|}{ Quadrant IV (high tax, low smoke-free) } \\
\hline New Hampshire & 7 & 73 & 1.78 \\
\hline New Mexico & 8 & 86 & 1.66 \\
\hline Texas & 8 & 23 & 1.41 \\
\hline Pennsylvania* & 9 & 82 & 1.60 \\
\hline Alaska & 15 & 50 & 2.00 \\
\hline Connecticut & 15 & 84 & 3.40 \\
\hline
\end{tabular}

\section{DISCUSSION}

The most notable finding from our national survey of state retail policy activities is that the retail environment is an emerging policy area for tobacco control in the US states. By 2014, all 50 states reported some type of retail policy activity. The average level of state policy activity increased by $168 \%$ within 2 years. In 2014, eight states exceeded the high score for 2012, and some states emerged as newly active leaders in this area. As state retail policy activity develops, continued surveillance will demonstrate how policies evolve, diffuse and expand.

Many states reported implementing policies that extend the ban on self-service for cigarettes to OTPs. While the FSPTCA banned self-service for cigarettes and smokeless tobacco products in all states, it did not cover OTPs such as cigars. ${ }^{17}$ In the absence of federal policy-before the recent Deeming Rule placing more tobacco products like cigarillos and e-cigarettes under FDA jurisdiction ${ }^{30}$ — states had been taking responsibility for making it more difficult to access unregulated tobacco products, especially flavoured products that are popular with youth. Not surprisingly, the most reported activity to-date was for ecigarettes, which reflects the rapid infiltration of these products in the retail environment ${ }^{31}$ and swift reactions from tobacco control coalitions and policymakers in many states to protect youth and establish e-cigarette MLAs. In our 2014 interviews, $76 \%$ of states reported having implemented an e-cigarette MLA, and since then, this number has grown to $96 \%$ (48 states). ${ }^{32}$ The licensing and density policy domain also shows many states with implemented policies, although these are typically state retail licensure laws established over the last few decades. More recent efforts to reduce density through licensing and zoning have seen success in a few states-from which others can now learn-to regulate the distance between tobacco retailers and places that youth frequent like schools and parks.

What states are not doing was as interesting as what they are doing. For example, the lack of progress towards non-tax approaches to increasing price was surprising, especially given the well-documented relationship between tobacco prices and use, particularly among youth, as well as new evidence about the role of price promotions in targeting price-sensitive consumers. ${ }^{19}$ In addition, few states reported any policy activity to restrict retail advertising or implement health warnings, which reflects the legal challenges associated with restricting commercial speech and the chilling effects of the 2010 lawsuit against graphic health warning signs in New York City. 513

While it is important to note the successful implementation of various retail policies in broad terms, we need to dive deeper into specific examples through qualitative assessment of policy development to effectively identify helpful resources that could translate to other policy environments. In addition, the reasons that some states have relatively little retail policy activity deserve attention. Future research should work to identify common barriers to retail policy development and resources that are available to states to enhance and support their retail policy efforts. ${ }^{18} 33$

It is important to note that the state-level scores reported here do not reflect planning or policy development occurring at the local level. For example, New York and Rhode Island's state scores do not reflect innovative policies recently passed in New York City and Providence. In the future, we will assess local activities, as we have recently interviewed a sample of local TCPs. It is also important to recognise the proliferation of electronic nicotine delivery systems since we began interviewing state programmes in 2012. Because of the contemporarily disproportionate interest in policy activity on these products, we have kept the e-cigarette domain separate for expository 
purposes. In the future, it may be more appropriate to merge each of these policies into a substantively relevant domain, for example, banning self-service into the product display domain. Finally, the Retail Policy Activity Score reflects the breadth and types of retail policy activities conducted, but does not assess the strengths or characteristics of any individual policy, nor does it assess the potential or observed impacts of policies, relative or absolute. For example, a strong minimum price law implemented at the state level receives the same score (4) as weaker minimum price laws. Studies that assess local level retail policies and individual policy strength would also help inform future retail policy planning.

\section{Recommendations}

States are poised to make rapid progress in designing and implementing new and innovative tobacco control retail policies. Despite many states' lack of progress in smoke-free air or excise taxes, many states are exploring retail policy activities such as proposals to raise the MLA to 21 and to reduce the density of tobacco retailers. Unfortunately, more than a quarter of states have no tobacco retailer licensing law, and retailer licensing has proven to be an indispensable tool for tobacco control, ${ }^{34}$ not only for understanding the retailer landscape and building an evidence base about tobacco industry influence, but also for implementing and enforcing all other retail tobacco policies.

The current study suggests that state and local TCPs require more capacity to promote evidence-based policymaking. Indeed, the observed change of retail policy activities was somewhat misaligned with the evidence base-the greatest increase in state policy activity was to regulate e-cigarettes, arguably the least harmful tobacco product. ${ }^{35}$ Over the two survey years, there was only a modest increase in non-tax mechanisms to increase the price of tobacco products, in spite of robust evidence that higher prices deter tobacco use, particularly among vulnerable populations. ${ }^{36}$ Progress towards evidence-based policymaking to regulate the retail environment requires better infrastructure for the rapid translation and dissemination of retail policy research that would inform strategic investment of limited state and local tobacco control resources to maximise public health benefits. Future research should consider how declines in tobacco control funding inhibit capacity to regulate the retail environment at the state and local level.

The tobacco industry represents a significant obstacle to promoting evidence-based policies. Indeed, 7 of the 10 top tobacco-growing states have low tobacco taxes and weak smokefree air laws (quadrant III). However, the industry's response to these and other regulations is also predictable. ${ }^{37}$ In the context of regulating the retail environment, more legal and other technical assistance is needed to help TCPs anticipate and counter the responses of the industry and its front groups.

The FDA should be concerned about the investment of state and local efforts to implement and enforce regulations that would be more effective at the federal level (eg, restricting availability of flavoured tobacco products that appeal to youth, increasing minimum price and package size, and communicating with consumers about potential harms of tobacco product use, in terms of ingredients and product design. ${ }^{38}$ Maximising federal regulation of tobacco products and marketing would free state and local TCPs to pursue other innovative policies that are outside of the FDA's domain and/or priorities, such as establishing tobacco-free pharmacies, reducing tobacco retailer density and using broad-based public health initiatives (eg, Healthy Stores for a Healthy Community), ${ }^{39}$ either to pass local policies or otherwise incentivise retailers to reduce the availability of tobacco products and visibility of tobacco marketing at the point of sale.

\section{What this paper adds}

- The 2009 passage of the Family Smoking and Prevention Tobacco Control Act in the USA clarified state and local authority to regulate the time, place, and manner of tobacco advertising and promotion.

- Beyond these types of strategies, other types of rule-making such as policies to address tobacco retailer density and efforts to raise prices through non-tax approaches are not directly addressed by federal law and thus devolved to states and communities.

- To date, no systematic survey of retail policy initiatives at the state level has been conducted; and little is known about what types of policies are being planned or implemented, or about which states are doing so.

- We describe states' retail tobacco policy activity from the first longitudinal study surveying state tobacco control programmes at two time points, 2012 and 2014.

- We demonstrate a dramatic increase in retail policy activity over the past several years.

- We compare retail policy progress in states to traditional tobacco control measures, namely smoke-free air laws and excise taxes.

Contributors DAL, SM-R, KMR, LH designed data collection tools, wrote the analysis plan, and drafted and revised the paper. DAL is guarantor. AAS, TC and CBR collected data, monitored data collection, analysed the data, and drafted and revised the paper.

Funding Funding for this study was provided by grant number U01 CA154281, the National Cancer Institute's State and Community Tobacco Control Initiative. The funders had no involvement in the study design, collection, analysis, writing or interpretation.

Competing interests KMR is the Chair of the Board of Directors of Counter Tools (http://countertools.org), a non-profit from which he receives compensation. Counter Tools provides technical assistance on point of sale tobacco control issues and distributes store mapping and store audit tools. KMR also has a royalty interest in a store mapping and audit system owned by the University of North Carolina at Chapel Hill but these systems were not used in this study. The other authors declare no conflicts of interest in this paper.

Ethics approval Ethics approval was obtained from the Institutional Review Board of Washington University in St Louis.

Provenance and peer review Not commissioned; externally peer reviewed.

Open Access This is an Open Access article distributed in accordance with the Creative Commons Attribution Non Commercial (CC BY-NC 4.0) license, which permits others to distribute, remix, adapt, build upon this work non-commercially, and license their derivative works on different terms, provided the original work is properly cited and the use is non-commercial. See: http://creativecommons.org/ licenses/by-nc/4.0/

\section{REFERENCES}

1 Federal Trade Commission. Federal Trade Commission Cigarette Report for 2013. Washington DC, 2016.

2 Counter Tobacco. The War in the Store. Secondary The War in the Store 2015. http://countertobacco.org/warinthestore

3 Henriksen L. Comprehensive tobacco marketing restrictions: promotion, packaging, price and place. Tob Control 2012;21:147-53.

4 U.S. Department of Health and Human Services, Centers for Disease Control and Prevention, National Center for Chronic Disease Prevention and Health Promotion, Office on Smoking and Health. Preventing tobacco use among youth and young adults: a report of the Surgeon General. Rockville, MD: U.S. Department of Health and Human Services, 2012.

5 Center for Public Health Systems Science. Point-of-sale strategies: a tobacco control guide. St Louis, MO: Center for Public Health Systems Science, George Warren Brown School of Social Work at Washington University in St Louis and the Tobacco Control Legal Consortium, 2014. 
6 Federal Trade Commission. Federal Trade Commission Smokeless Report for 2012. Washington DC, 2015.

7 Reitzel LR, Cromley EK, Li Y, et al. The effect of tobacco outlet density and proximity on smoking cessation. Am J Public Health 2011;101:315-20.

8 Watkins KL, Regan SD, Nguyen N, et al. Advancing cessation research by integrating EMA and geospatial methodologies: associations between tobacco retail outlets and real-time smoking urges during a quit attempt. Nicotine Tob Res 2014;16(Suppl 2):S93-101.

9 Robertson L, Cameron C, McGee R, et al. Point-of-sale tobacco promotion and youth smoking: a meta-analysis. Tob Control Published Online First: 4 Jan 2016. doi:10.1136/tobaccocontrol-2015-052586

10 Henriksen L, Schleicher NC, Dauphinee AL, et al. Targeted advertising, promotion, and price for menthol cigarettes in California high school neighborhoods. Nicotine Tob Res 2012;14:116-21.

11 Lee JG, Henriksen L, Rose SW, et al. A systematic review of neighborhood disparities in point-of-sale tobacco marketing. Am J Public Health 2015;105:e8-18.

12 Rodriguez D, Carlos HA, Adachi-Mejia AM, et al. Predictors of tobacco outlet density nationwide: a geographic analysis. Tob Control 2013;22:349-55.

13 Tobacco Control Legal Consortium. Restricting Tobacco Advertising. 2011. http:/l www.publichealthlawcenter.org/sites/default/files/resources/tclc-guiderestricttobadvert-2011.pdf (accessed 22 Sep 2015).

14 Chapman S, Freeman B. Regulating the tobacco retail environment: beyond reducing sales to minors. Tob Control 2009;18:496-501.

15 Centers for Disease Control and Prevention. Designing and implementing an effective tobacco counter-marketing campaign. Atlanta, GA: US Department of Health and Human Services, Centers for Disease Control and Prevention, National Center for Chronic Disease Prevention and Health Promotion, Office on Smoking and Health, First Edition October 2003.

16 Luke DA, Stamatakis KA, Brownson RC. State youth-access tobacco control policies and youth smoking behavior in the United States. Am J Prev Med 2000;19:180-7.

17 U.S. Food and Drug Administration. Overview of the Family Smoking Prevention and Tobacco Control Act Secondary Overview of the Family Smoking Prevention and Tobacco Control Act 2015. http://www.fda.gov/TobaccoProducts/ GuidanceComplianceRegulatoryInformation/ucm246129.htm

18 Lange T, Hoefges M, Ribisl KM. Regulating tobacco product advertising and promotions in the retail environment: a roadmap for states and localities. J Law Med Ethics 2015;43:878-96.

19 Golden SD, Smith MH, Feighery EC, et al. Beyond excise taxes: a systematic review of literature on non-tax policy approaches to raising tobacco product prices. Tob Control 2016;25:377-85.

20 Roeseler A, Solomon M, Beatty C, et al. The tobacco control network's policy readiness and stage of change assessment: what the results suggest for moving tobacco control efforts forward at the state and territorial levels. J Public Health Manag Pract 2016;22:9-19.

21 Schmitt CL, Lee YO, Curry LE, et al. Research support for effective state and community tobacco control programme response to electronic nicotine delivery systems. Tob Control 2014;23(Suppl 3):iii54-7.

22 Pacheco J. The social contagion model: exploring the role of public opinion on the diffusion of antismoking legislation across the American States. J Polit 2012;74:187-202.
23 Shipan $C R$, Volden C. Bottom-up federalism: the diffusion of antismoking policies from U.S. cities to states. Am J Polit Sci 2006;50:825-43.

24 National Association of Tobacco Outlets. State Tax Increase Legislation. Secondary State Tax Increase Legislation 2016. http://www.natocentral.org/?page_ id $=2603$

25 Centers for Disease Control and Prevention. Grants Notice: CDC-RFA-DP15-1509. Secondary Grants Notice: CDC-RFA-DP15-1509 2014. http://www.grants.gov/web/ grants/search-grants.html?keywords=DP15-1509

26 Centers for Disease Control and Prevention (CDC). State cigarette minimum price laws_-United States, 2009. MMWR Morb Mortal Wkly Rep 2010;59: 389-92.

27 Tynan MA, Ribisl KM, Loomis BR. Impact of cigarette minimum price laws on the retail price of cigarettes in the USA. Tob Control 2013;22:e78-85.

28 American Lung Association. State of tobacco control 2014. Washington DC: The American Lung Association, 2015.

29 Centers for Disease Control and Prevention. . Best Practices for Comprehensive Tobacco Control Programs - 2014. Atlanta: U.S. Department of Health and Human Services, Centers for Disease Control and Prevention, National Center for Chronic Disease Prevention and Health Promotion, Office on Smoking and Health, 2014.

30 U.S. Food and Drug Administration. FDA takes significant steps to protect Americans from dangers of tobacco through new regulation. 2016. http://www.fda. gov/NewsEvents/Newsroom/PressAnnouncements/ucm499234.htm

31 Schleicher NC, Johnson T, Ahmad I, et al. Tobacco Marketing in Californias Retail Environment. Secondary Tobacco Marketing in Californias Retail Environment 2015. http://www.cdph.ca.gov/programs/tobacco/Documents/Resources/Publications/ Tobacco\%20Marketing\%20in\%20Californias\%20Retail\%20Environment Notations_Final\%202.9.16.pdf

32 National Conference of State Legislatures. Alternative Nicotine Products, Electronic Cigarettes. Secondary Alternative Nicotine Products, Electronic Cigarettes 2016 http://www.ncsl.org/research/health/alternative-nicotine-products-e-cigarettes.aspx

33 Luke D, Moreland-Russell S, Combs T, et al. Point-of-sale Report to the Nation: policy activity 2012-2014. Secondary Point-of-sale Report to the Nation: policy activity 2012-2014. 2015. http://cphss.wustl.edu/Products/ProductsDocuments/ ASPiRE_2015_ReportToTheNation.pdf\#PointofSaleReporttotheNation: PolicyActivity2012-2014

34 McLaughlin I. License to kill?: Tobacco retailer licensing as an effective enforcement tool. Consortium TCL, 2010.

35 Johnson D, Lester J, Berman M. The FDA's misplaced priorities: premarket review under the Family Smoking Prevention and Tobacco Control Act. Tob Control 2016;25:246-53.

36 Contreary KA, Chattopadhyay SK, Hopkins DP, et al. Economic impact of tobacco price increases through taxation: a community guide systematic review. Am J Prev Med 2015;49:800-8.

37 Savell $E$, Gilmore $A B$, Fooks $G$. How does the tobacco industry attempt to influence marketing regulations? A systematic review. PLOS ONE 2014; 9:e87389.

38 Berman M. Regulatory oversight of ENDS product defects. Tob Control Published Online First: 25 Apr 2016. doi:10.1136/tobaccocontrol-2016-052985

39 Healthy Stores for a Healthy Community. Secondary Healthy Stores for a Healthy Community 2014. http://healthystoreshealthycommunity.com/ 